\title{
Circuit
}

Musiques contemporaines

\section{Hommage : Claude Vivier, en mémoire, en présence}

\section{Gilles Tremblay}

Volume 5, numéro 1, 1994

Gilles Tremblay : réflexions

URI : https://id.erudit.org/iderudit/902094ar

DOI : https://doi.org/10.7202/902094ar

Aller au sommaire du numéro

Éditeur(s)

Les Presses de l'Université de Montréal

ISSN

1183-1693 (imprimé)

1488-9692 (numérique)

Découvrir la revue

Citer cet article

Tremblay, G. (1994). Hommage : Claude Vivier, en mémoire, en présence.

Circuit, 5(1), 63-65. https://doi.org/10.7202/902094ar d'utilisation que vous pouvez consulter en ligne.

https://apropos.erudit.org/fr/usagers/politique-dutilisation/ 


\section{Claude Vivier, en mémoire, en présence}

Paru dans la Revue de musique des universités canadiennes, $n^{\circ} 4$, 1983, pp. 3-5.

Claude Vivier, d'une lettre à une amie (janvier 1983):

... Je dois composer d'arrache-pied, donner aux êtres humains une musique qui les empêchera une fois pour toute de faire la guerre. Une phrase me vient à l'esprit: « C'est ma propre mort que je célèbrerai ». Je ne sais pas pourquoi il me semble que je veuille vaincre la mort sur son propre terrain, la rendre libératrice de l'être ouvert sur l'éternité. Donner aux humains une telle musique que leur conscience débouche directement sur l'éternité sans passer par la mort, sans payer un tribut au vieux Passeur de l'Achéron!

Au journal Le Monde, paru le 15 mars 1983:

* Ce n'est pas moi qui écris ma musique. C'est peutêtre les fleurs que j'ai senties, les gestes que j'ai faits, les êtres que j'ai vus, ou les étoiles, on ne sait jamais. La musique est amour, comme tout est amour $»$.

Ef toujours à une amie:

... Je ne crois pas que dans les prochaines années je compose autant qu'avant. Je dois tout raffiner, trouver cette voix de l'enfant solitaire voulant embrasser le monde de son amour candide - cette voix que tous entendent et veulent habiter éternellement. Comme c'est étrange. Malgré tout ce que je t'ai dit sur l'adulte que j'étais devenu, la seule voix qui perce en moi, c'est celle de l'enfant qui parle doucement aux anges le soir! Tout autour de moi, c'est le silence.

Claude Vivier, c'était l'esprit d'enfance parmi nous.

II aimait vivre et il en était ravi : "Je suis content d'être né ", me ditil un jour, lorsqu'il avait vingt ans. Sa soif de connaître, ainsi que son enthousiasme ont été mes premières impressions lorsque je l'ai eu comme élève au Conservatoire, un élève très exigeant pour son guide! Nous avons beaucoup travaillé, dans un esprit de grande rigueur, nous émerveillant ensemble aux 
beautés des musiques contemplées. Outre les classiques, le chant grégorien, la rythmique grecque, les contemporains, nous avions analysé ensemble le Wozzeck d'Alban Berg. Mais ce fut surtout pour moi la joie, et la fierté, d'être le premier à découvrir et à reconnaître ses dons immenses de compositeur. II fut pour tous ses professeurs et ses camarades d'alors, et plus tard pour ses amis et collègues interprètes entre autres, une source constante d'enrichissement. Claude étudia aussi en Allemagne avec Karlheinz Stockhausen pour qui il avait une grande admiration. Très doué pour les langues, il fit de nombreux séjours à l'étranger, dont un à Bali. Sa bonne humeur était un tonique, nous garderons longtemps dans l'oreille son rire légendaire.

Ce compositeur, travailleur infatigable, en était arrivé à une grande maîtrise de ses moyens, totalement voué à son œuvre et à la musique, en un engagement profond, avec les risques que cela implique. L'œuvre était déjà impressionnante, avec une prédilection pour la musique vocale: Ojikawa, Prolifération, Chants, Liebesgedichte, Pulau Dewata, Shiraz, Journal, Lonely Child, l'Opéra Kopernikus, Prologue pour un Marco Polo, Wo bist du Licht? (où es-tu lumière ?), et sa dernière composition non terminée: Crois-tu en l'immortalité de l'âme?

Autant de titres, pour n'en citer que quelques-uns, où circulent les grands thèmes de son cuvre: l'amour, la mort, l'origine (la mère), la féerie, le voyage, la lumière.

Soudain, il n'est plus là.

L'absence, le vide, en notre espace, en notre temps, sont habités par sa pensée dont l'esprit est maintenant dans un autre espace hors de l'espace, dans un autre temps hors du temps, mais communicants cependant. « Le temps est semence d'éternité ». (Newman) Cet espace et ce temps de l'absence ne doivent pas rester inertes. Inspirés par l'esprit laissé, ils appellent intensément, comme un aimant au cœur même du vide, la plénitude de la vie féconde, devenant ainsi déjà signe de résurrection.

Nous vivons une période de violence inouïe qui coïncide aussi avec le mépris des valeurs qui font vivre. La brutalité de sa mort le rend fraternel à toutes les victimes et de quelque époque qu'elles soient, compassion dont le Christ ressuscité est l'espérance. Un ami commun m'écrivait en apprenant sa mort: «Maintenant il est en présence du seul être vraiment fascinant: le Dieu trois fois saint. Comme vous, je crois qu'il « voit Dieu » que l'Évangile présente comme miséricorde infinie, comme Celui qui accueille sans poser de condition l'enfant qui se tourne, aimant, vers Lui..." . 
D'ami, de collègue, de camarade, Claude Vivier est maintenant devenu père aussi pour l'héritage précieux et exemplaire qu'il nous laisse en plus de son œuvre: l'esprit d'enfance. En son abandon même il chante la résurrection.

$\grave{A}$ la fin de son cuvre Lettura di Dante, la voix murmure HO VISTO DIO. Treize fois.

Oui, tu vois Dieu,

Claude, à Dieu. 